\title{
Genome-wide analyses of Epstein-Barr virus reveal conserved RNA structures and a novel stable intronic sequence RNA
}

\author{
Walter N Moss and Joan A Steitz ${ }^{*}$
}

\begin{abstract}
Background: Epstein-Barr virus (EBV) is a human herpesvirus implicated in cancer and autoimmune disorders. Little is known concerning the roles of RNA structure in this important human pathogen. This study provides the first comprehensive genome-wide survey of RNA and RNA structure in EBV.

Results: Novel EBV RNAs and RNA structures were identified by computational modeling and RNA-Seq analyses of EBV. Scans of the genomic sequences of four EBV strains (EBV-1, EBV-2, GD1, and GD2) and of the closely related Macacine herpesvirus 4 using the RNAz program discovered 265 regions with high probability of forming conserved RNA structures. Secondary structure models are proposed for these regions based on a combination of free energy minimization and comparative sequence analysis. The analysis of RNA-Seq data uncovered the first observation of a stable intronic sequence RNA (sisRNA) in EBV. The abundance of this sisRNA rivals that of the well-known and highly expressed EBV-encoded non-coding RNAs (EBERs).

Conclusion: This work identifies regions of the EBV genome likely to generate functional RNAs and RNA structures, provides structural models for these regions, and discusses potential functions suggested by the modeled structures. Enhanced understanding of the EBV transcriptome will guide future experimental analyses of the discovered RNAs and RNA structures.
\end{abstract}

Keywords: Epstein-Barr virus (EBV), Herpesvirus, RNA, RNA structure, Non-coding RNA (ncRNA), RNA-Seq, Bioinformatics, W repeat, sisRNA, RNA editing

\section{Background}

Epstein-Barr virus (EBV) is widely disseminated in the human population. Upwards of $95 \%$ of the adult human population is infected with EBV [1]. EBV is implicated in a number of different cancers, including Hodgkin's disease [2], nasopharyngeal carcinoma [3], hepatocellular carcinomas [4], lymphoepithelioma-like carcinomas [5], some breast cancers [6], and in autoimmune disorders such as Sjögren's syndrome [7], dermatomyositis [8], lupus [9], rheumatoid arthritis [10], and multiple sclerosis [11]. EBV was the first cancer-associated virus to be discovered when in 1964 [12] it was isolated from tumors occurring in African children (Burkitt's lymphoma [13]).

\footnotetext{
* Correspondence: joan.steitz@yale.edu
Department of Molecular Biophysics and Biochemistry, Howard Hughes

*Correspondence: joan.steitz@yale.edu
Department of Molecular Biophysics and Biochemistry, Howard Hughes

Medical Institute, Yale University School of Medicine, New Haven, Connecticut 06536, USA
}

Despite intense investigation for more than 50 years, the precise roles played by the virus in these diseases remains to be elucidated.

The $\sim 170000$ bp genome of EBV is a linear doublestranded (ds)DNA that circularizes to form an episome in the host cell nucleus. Infection occurs by entry of the EBV virion into human host epithelial cells and initially proceeds via an aggressive lytic phase. The virus migrates to $\mathrm{B}$ cells where it causes persistent lifelong infections marked by extended periods of latency with interspersed lytic reactivation [14]. EBV latency proceeds via three distinct programs, each expressing a different set of coding and non-coding viral gene products. Viral latent gene products rewire B cells to evade the host immune system and propagate the virus [15]. In a manner not yet fully understood, this rewiring increases the tumorigenic potential of EBV-infected cells, including making infected cells 
resistant to apoptotic pathways that would otherwise kill cancerous cells [16].

The EBV transcriptome is complex, consisting of multiple pre-mRNA transcripts that undergo extensive alternative splicing events and can, at various states of infection, yield different sets of gene products [17]. Two well-studied EBV-encoded ncRNAs (EBER1 and EBER2) are known to be expressed throughout infection [18], as are subsets of as many as 50 different EBV-encoded microRNAs (miRNAs) $[19,20]$. Although the precise functions of the EBERs have remained obscure, they are the most highly expressed RNAs in EBV-infected cells $\left(\sim 10^{7}\right.$ copies per cell [18]). Roles in cancer have been proposed [21] and the EBERs are capable of inducing tumors in immunesuppressed mice [22]. Both EBERs form ribonucleoprotein complexes [23-26], including host proteins, and adopt well-defined secondary structures [27]. Except for the EBERs, RNA structure is a relatively understudied aspect of EBV virology; an analysis of RNA secondary structure in EBV could enable significant advances in understanding this important human pathogen.

RNA secondary structure plays important roles in many viruses, mediating functions as diverse as translation initiation [28], catalysis [29], viral genome packaging [30], alternative splicing [31,32], interactions with the host innate immune system [33], RNA lifetime/stability [34-36], and regulation of gene expression [37]. The discovery of RNA structure is an active area of research [38-40] and is aided by the availability of sophisticated non-coding (nc)RNA-discovery algorithms [41-43]. A successful strategy for discovering conserved RNA structures is implemented in the program RNAz [44]. In this approach, homologous sequences are aligned and divided into fragments. For each fragment, calculated parameters that include measures of the thermodynamic stability (z-score [45]) and conservation of secondary structure are used to make predictions based on a support vector machine (SVM) trained on known ncRNAs, which generates a probability classifier ( $\mathrm{p}$-class, scale of 0.0 to 1.0) for the fragment containing conserved secondary structure. The RNAz approach has been used to discover RNA secondary structures in a number of viruses [38,46-48].

\section{Results and discussion Global findings}

RefSeq genomes ( 170 kbp long) from four EBV strains (NC_007605.1, NC_009334.1, AY961628.3, HQ020558.1) and one from the closely-related (Figure 1) Macacine herpesvirus 4 (MHV4, NC_006146.1; also known as rhesus lymphocryptovirus) were aligned using the MAFFT alignment program $[49,50]$. The average pairwise sequence identity (APSI) of the alignment is $84.8 \%$; the four EBV strains were close in sequence (APSI of 95.6\%), while MHV4 had an APSI of 68.6\% versus EBV.

Across the entire EBV genome the z-score average is -0.19 and the average p-class is 0.13 . RNAz discovered 265 regions that map to known transcripts from the EBV genome (named locus 1 to 265 in Additional files 1 and 2) and have strong evidence of locally conserved and stable RNA structure. These regions (average length 200 nt) are comprised of overlapping windows with high predicted probability of generating conserved RNA structure. The average p-class for the set of predictions was 0.91 with minimum and maximum values of 0.61 and 1.00 , respectively (Additional file 1). The thermodynamic z-score is an important component in determining the p-class. This parameter reflects the thermodynamic stability of the native sequence predicted structure versus that of random sequence [45] (e.g. measures greater than expected folding stability). For predicted structured regions in EBV RNA, the average z-score was -2.38 with minimum and maximum values of -1.18 and -9.71 , respectively. This analysis,

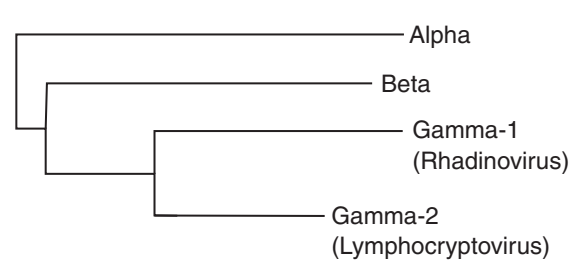

$\overline{0.1}$ divergence

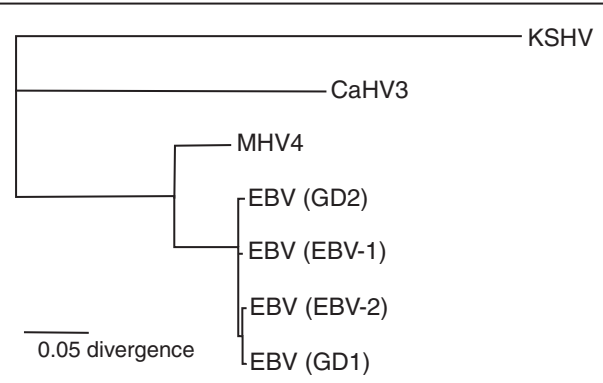

Figure 1 Phylogenic relationships of analyzed viruses. (Left) Phylogenetic tree showing the three herpesviridae sub-families (alpha, beta, and gamma), where the gamma sub-family is further divided into two genera: gamma-1 (Rhadinovirus) and gamma-2 (Lymphocryptovirus). The tree was generated from data in [51]. (Right) Breakdown of the gamma herpesvirus branch shown on the left. The consensus neighbor-joining tree (100 replicates) was based on the conserved herpesvirus DNA polymerase catalytic subunit (DPOL). Kaposi's sarcoma-associated herpesvirus (KSHV), a gamma-1 herpesvirus, is used as an outgroup to illustrate the phylogenetic relationships between four EBV strains (EBV-1, EBV-2, GD1, and GD2) and two other lymphocryptoviruses used in this study [Macacine herpesvirus 4 (MHV4) and Callitrichine herpesvirus 3 (CaHV3)]. The tree was generated using the Geneious program. 
however, does not account for long-range RNA interactions that may occur outside the overlapped prediction windows.

\section{Identification of known EBV ncRNAs}

The genomic region specifying EBER1 occurs within locus 12 (Additional file 1). The structure model derived for EBER1 (Figure 2A) is almost identical to the model in the Rfam database (ID\# RF01789). A single base pair in the Rfam model, between nt 6760 and 6770, is shifted to form a pair between 6646 and 6770 , and the predicted closing AU pair of this hairpin is open in the Rfam model (Figure 2A). Additionally, C6649 is in a bulgeloop in the Rfam model, but the insertion of a $G$ residue across from this nt allows a GC pair to form. EBER2, surprisingly, does not occur in an RNAz-predicted locus. The region containing EBER2 was not calculated to have a favorable z-score; however, this is most likely due to the inability of the primary sequence alignment to capture the conservation of structure for this RNA. EBER2 is less conserved in sequence than EBER1 (50.3\% sequence conservation vs. $78.3 \%$ for EBER1) making primary sequence alignment difficult in this region. Common helices in EBER2 were not properly aligned, thus reducing the predicted free energy of the consensus structure, which resulted in an unfavorable z-score.

All but two of the EBV miRNAs annotated in the miRBase database [53] occur in RNAz-predicted structured regions. Each of the mature miRNA sequences, when mapped to predicted structure models, falls within a hairpin RNA structure that resembles a canonical premiRNA (Additional files 1 and 3). For example, Figure 2B shows three hairpins in locus 209, which include the BART3, BART4, and BART1 miRNAs. Each of these hairpins places the $5 \mathrm{P}$ and $3 \mathrm{P}$ mature sequences in canonical structural contexts: the mature miRNAs are offset and imperfectly base pair with each other. This is also true for the other 36 mature miRNA sequences that fall within predicted structured regions (Additional file 3).

Finally, a reported EBV-encoded viral small nucleolar RNA (v-snoRNA; [52]) also falls within an RNAz-predicted structured region (locus 235 in Additional file 1). The v-snoRNA corresponds to nt 154352 to 154416 (Additional file 3) and, in isolation, has a predicted folding free energy and $\mathrm{z}$-score of $-17.8 \mathrm{kcal} / \mathrm{mol}$ and -0.81 , respectively (Figure 2C).

In addition to the regions corresponding to EBER1, the v-snoRNA, and 14 loci specifying EBV pre-miRNAs,

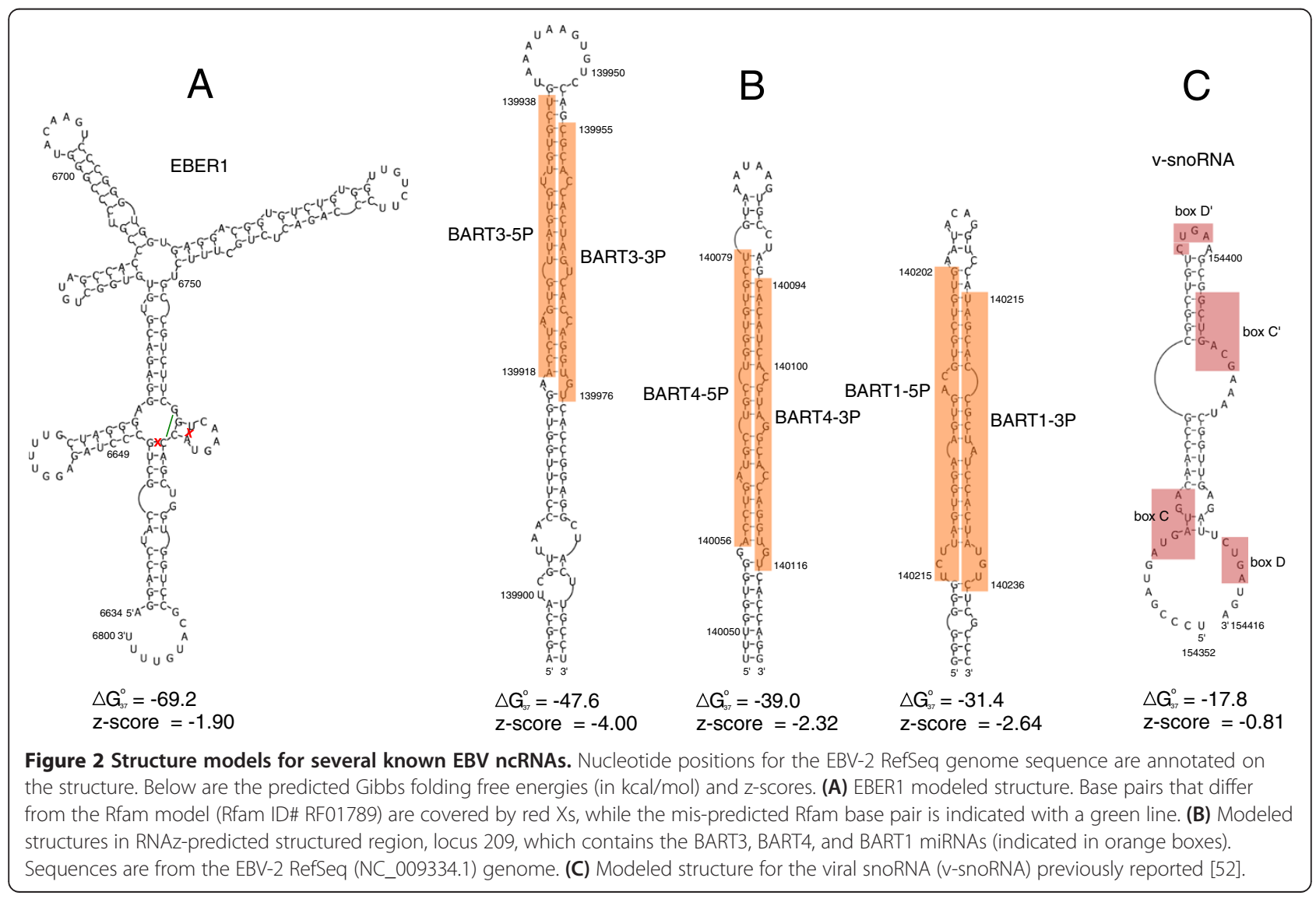


there are 249 additional EBV regions with predicted conserved RNA structure (Additional file 1).

\section{Structure within introns}

Sixty predicted structured regions overlap introns. Introns are a fertile source of structured ncRNAs [54,55] that play roles in a number of important biological processes: snoRNAs [56], miRNAs [57], and piRNAs [58] are expressed from introns. RNA structure within introns can alter accessibility or distance between functional elements and thus regulate splicing [59].

The most extensive regions of predicted structure in introns occur within a repetitive region of the EBV genome (the $\mathrm{W}$ repeats). The number of $\mathrm{W}$ repeats can vary, and the optimal number appears to be five to eight [60]. The W repeats are transcribed at the $5^{\prime}$ end of the long ( 100000 nt) primary transcript encoding the Epstein-Barr nuclear antigen (EBNA) latent proteins (Figure 3). EBNA transcripts are particularly interesting because they have high nuclear-to-cytoplasmic abundance, suggesting noncoding nuclear functions [61].

Six EBNA proteins are expressed from mRNAs produced by extensive alternative splicing. Transcription of the EBNA RNA can occur from an upstream promoter, the $\mathrm{C}$ promoter $(\mathrm{Cp})$, or a downstream $\mathrm{W}$ promoter (Wp) [62]. Early in latency III Wp is utilized, where splicing of W0 to W1 generates the start codon for EBNALP production [63]; later in latency III there is a switch to $\mathrm{Cp}$ where the non-coding $\mathrm{C} 2$ exon is joined to $\mathrm{W} 1$ to create the EBNA-LP start codon (Figure 3). Within the $\mathrm{W}$ repeats two short coding exons, W1 and W2, which are 66 and 132 nt long, respectively, are joined to form the EBNA-LP protein open reading frame (ORF) by removal of a long (2791 nt) and short (81 nt) intron. RNAz predicts widespread conserved and stable RNA structure covering $49 \%$ of the long W repeat intron. There are five predicted regions, which are identical in sequence in the W repeats (Figure 3): loci 18, 23, 28, 33, 38, 43, 48, and 53 are identical; loci 19, 24, 29, 34, 39, 44, 49, and 54 are identical; loci 20, 25, 30, 35, 40, 45, and 50 are identical; loci $21,26,31,36,41,46$, and 51 are identical; and finally, loci 22, 27, 32, 37, 42, 47, and 52 are identical. Loci 18, 19 , and 20, although they are multiplied in the W repeats, are transcribed only when $\mathrm{Cp}$ is used to initiate transcription (Figure 3). Cp occurs just upstream of locus 17 and the $\mathrm{C} 1$ non-coding exon is within locus 17 (Figure 3). The first copy of Wp overlaps locus 21, which also contains W0 (Figure 3).

Within loci $18,23,28,33,38,43,48$, and 53 is a highly unusual modeled RNA structure, a very long (586 nt) tetraloop hairpin (Figure 4A). The INFERNAL package $[64,65]$ was used to search for additional homologous structures. Three other lymphocryptovirus species [MHV4, Callitrichine herpesvirus 3 (CaHV3), and Cercopithecine herpesvirus 12 (CeHV12, also known as papiine herpesvirus)], members of the herpesvirus taxonomical group to which EBV belongs (Figure 1), possess homologous structures. These discovered hairpins occur within the long introns of repeats homologous to the W repeats of EBV, appearing six times in MHV4 (NC_006146.1 nt 12738 to 13335,15820 to 16416,18901 to 19497,21982 to 22578 , 25063 to 25659 , and 28144 to 28740 ) and 4 times in CaHV3 (NC_004367.1 in the negative strand nt 120959 to 121293,123871 to 124205,126783 to 127117 , and 129695 to 130029). Three hairpin homologs are found within the partial sequence of CeHV12 (AF200364.1 nt 6498 to 7112, 9542 to 10156,12586 to 13200$)$.

The APSI of these long hairpin sequences is $66.7 \%$, with the CaHV3 sequence being most distant (APSI 45.1\% versus EBV). The MHV4 and CeHV12 hairpins are most similar to EBV in sequence (APSI of $80.5 \%$ and $74.5 \%$, respectively) and structure (Figure $4 \mathrm{~B}$ and $\mathrm{C}$ and

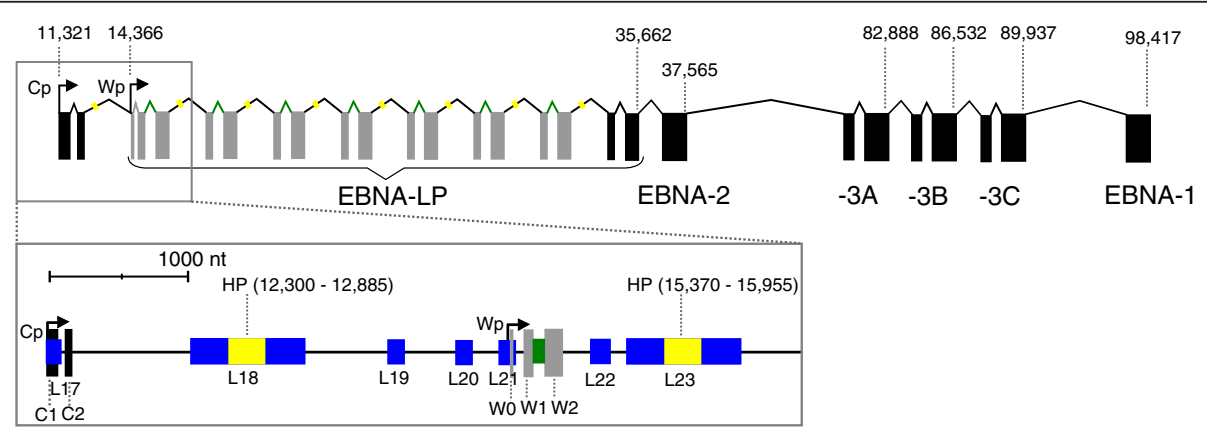

Figure 3 Cartoon of the primary transcript encoding the EBNA proteins. Exons are indicated with black or grey rectangles and the genomic location of the end of each protein-coding region is indicated above. The identical W1 and W2 coding exons that compose most of EBNA-LP are shown in grey. The Cp and upstream Wp promoter sites are indicated by bent arrows with the genome coordinates of the transcription start sites given above. The boxed region zooms in to show the 5' end of the pre-mRNA, including the locations of the predicted long hairpin (HP) and ebv-sisRNA-1, colored yellow and green, respectively, with their genome coordinates given in parentheses. RNAz-predicted structured regions are shown in blue and labeled L17 to L23 for loci 17 to 23 (genome coordinates for these loci are in Additional file 1). 
Figure 4 Structure models for lymphocryptovirus repeat long

hairpin RNAs. A reported A-to-l editing site [66] is indicated with a red

"l". Shown are sequences from (A) Epstein-Barr virus (EBV), (B) Macacine herpesvirus 4 (MHV4), (C) Cercopithecine herpesvirus 12 (CeHV12), and (D) Callitrichine herpesvirus 3 (CaHV3).

Additional file 4). The EBV, MHV4, and CeHV12 hairpins are each capped with a tetraloop closed by a GC pair (Figure $4 \mathrm{~A}, \mathrm{~B}$, and $\mathrm{C}$ ) and only the first nt in the loop varies (UUGG, CUGG, and GUGG, respectively). The more distant CaHV3 hairpin, in contrast, is capped with a seven-nt loop (Figure 4D). Perhaps the identities of the capping nucleotides are of lesser importance to the function of this long hairpin than the overall conserved structure, which is marked by extensively base paired stem regions interspersed with internal (or bulged) loops (Figure 4). Internal loops may adopt interesting 2D and 3D structures; for example, the three-by-three internal loop that occurs 20 bps from the hairpin loop in EBV [Figure 4A, also conserved in MHV4 (Figure 4B)], may fold into a "3 RRs" motif [67] where the opposing internal loop nucleotides form consecutive sheared purinepurine pairs.

Additionally, global thermodynamic z-scores were calculated for each hairpin (Figure 4): all four have very negative $\mathrm{z}$-scores (ranging from -6.3 to -5.9 ). Thus, the structures generated by these sequences are more than six standard deviations more thermodynamically stable than random sequences with the same dinucleotide content. This indicates that evolution is acting to preserve base pairing within each sequence, as well as the striking structural homology between these viral hairpins.

Very long RNA hairpins that are structurally similar to the EBV W repeat hairpin have been described in humans [68] and in Caenorhabditis elegans [69]. These structures are excellent substrates for adenosine deaminase acting on RNA (ADAR) editing enzymes, which convert adenosine to inosine (A-to-I editing). Interestingly, a previous study of A-to-I editing in EBV [66] found evidence for an editing site that maps to a region of the genome that we predict to be part of the long hairpin (Figure 4A). ADARs act on structured RNAs and have preferences for adenosines in particular sequence contexts [70], allowing the prediction of potential A-to-I editing sites and of the extent of editing. The reported editing site is predicted to be moderately edited ( $12.9 \%$ by ADAR2, Additional file 4 ) and is modeled to be in a CA internal loop (Figure 4A). There are additional sites predicted to be strongly edited in the EBV W repeat hairpin and in the homologous structures found in MHV4, CeHV12, and CaHV3 (Additional file 4). Few of these strongly predicted sites (seven), 


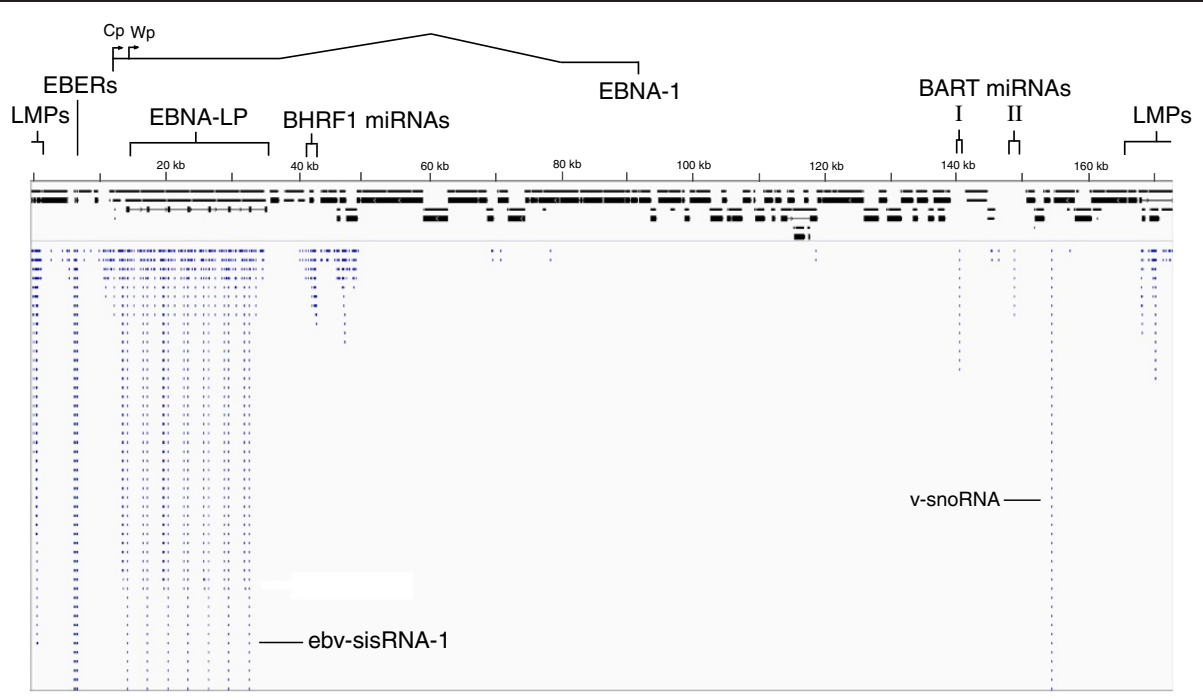

Figure 5 Small RNA library RNA-Seq reads aligned with the EBV genome. Reads are colored blue; the EBER1, EBER2, and sisRNA peaks are much larger than the represented area (see Table 1). A cartoon of the EBV genome is shown in black (exons as boxes and introns as thin lines). The locations of latently expressed genes [EBNA-LP, LMPs, EBERs (EBER1 and EBER2), BHRF1 miRNAs, and BART miRNAs (clusters I and II)] are indicated at the top of the figure, including the location of the $\mathrm{Cp}$ and first Wp promoter sites for producing mRNA for the EBNA-LP and five other EBNA proteins (additional details are in Figure 3). Peaks for the ebv-sisRNA-1 and v-snoRNA are indicated. Images were generated using the integrated genome viewer (IGV, [76,77]) with data from Additional file 5.

however, have apparent conservation (Additional file 4), which is unsurprising, as selection of ADAR sites may be partially stochastic [71].

RNA editing in introns, typically within Alu inserts [71], has been proposed to regulate RNA splicing [72]. Inosine can form wobble pairs with $\mathrm{G}$ and $\mathrm{C}$ residues and can contribute to RNA-protein interactions: thus A-to-I editing can alter important RNA-RNA and RNA-protein interactions [73]. Editing can alter splicing regulatory elements or create/destroy splice sites [72]. Perhaps editing of this long intronic hairpin also plays a role in splicing or in other functions post-splicing.

\section{Discovery of an EBV-encoded sisRNA}

A small RNA library (30-200 nt size range) was constructed using nuclear RNA isolated from cultured human B lymphocytes stably infected with EBV (BJAB-B1 cells [74]). These cells exhibit a latency III program of gene expression, the most transcriptionally active program, which also produces latency I and II transcripts. Nuclear RNAs include not only EBER1 and EBER2 [75] but also intronic sequences that are excised during the splicing process. Unsurprisingly, the abundant EBER1 and EBER2 are present in the library and had the highest number of aligned RNA-Seq reads (Figure 5 and Table 1). A significant peak ( 7.8\% EBER1 abundance) corresponding to the v-snoRNA (Figure 5 and Table 1) was also observed. There was a surprisingly large peak originating from the $\mathrm{W}$ repeat region (Figure 5). This peak corresponds to reads that cover the entirety of the small intron (81 nt) that separates the W1 and W2 ORFs (Figure 3). Next to the EBERs, this was the largest peak observed. Comparing length-normalized reads between the intron and EBER1, the intron is estimated to be present at $21 \%$ the level of EBER1 or roughly on a par with EBER2, which is estimated to be $25 \%$ as abundant as EBER1 (Table 1). The presence of the intron in total nuclear RNA samples was confirmed by Northern blot (Figure 6A) and RT-PCR (Figure 6B). RT-qPCR then revealed that the intron is $\sim 9$-fold enriched in nuclear versus cytoplasmic RNA (Figure 6C).

Stable intronic sequence (sis)RNAs have been described in Xenopus oocytes [78] and, interestingly, in herpes simplex virus-1 (HSV-1, an $\alpha$-herpesvirus) [79] and in cytomegalovirus (a $\beta$-herpesvirus) [80]. In these

Table 1 Regions with significant peaks in aligned RNA-Seq reads for undigested samples

\begin{tabular}{lccccc}
\hline & $\mathbf{5}^{\prime} \mathbf{n t}$ & $\mathbf{3}^{\prime} \mathbf{n t}$ & Reads & Length (nt) & \% EBER1 \\
\hline EBER1 & 6634 & 6800 & 1610 & 167 & 100.0 \\
EBER2 & 6961 & 7133 & 415 & 173 & 24.9 \\
ebv-sisRNA-1 & - & - & 162 & 81 & 20.7 \\
V-snoRNA & 154352 & 154416 & 49 & 65 & 7.8 \\
Short intron & 952 & 1025 & 41 & 74 & 5.7 \\
Short intron & 789 & 870 & 32 & 82 & 4.0 \\
Short intron & 459 & 539 & 21 & 81 & 2.7 \\
Short intron & 170112 & 170189 & 15 & 78 & 2.0 \\
\hline
\end{tabular}

*Percent abundance vs. EBER1. 


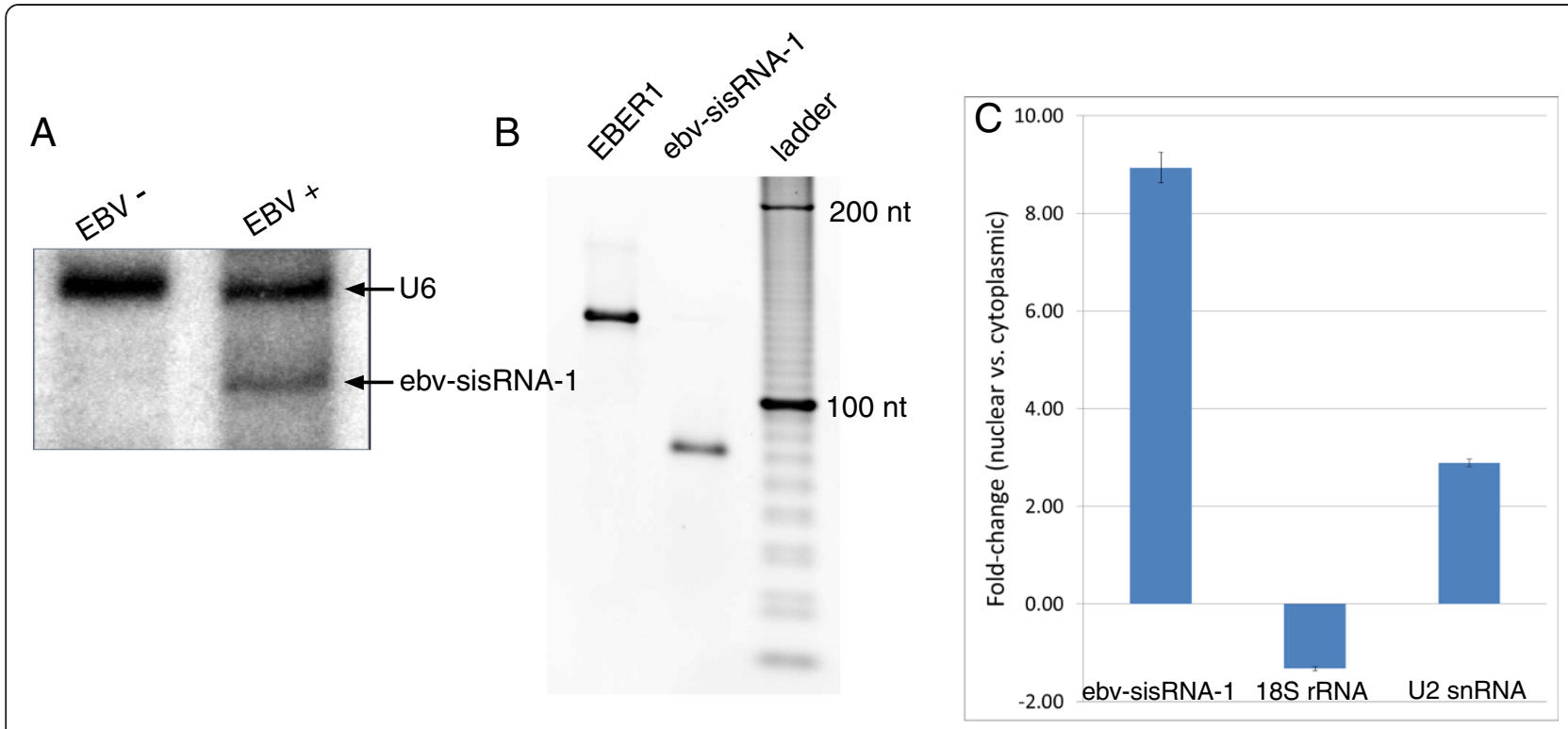

D
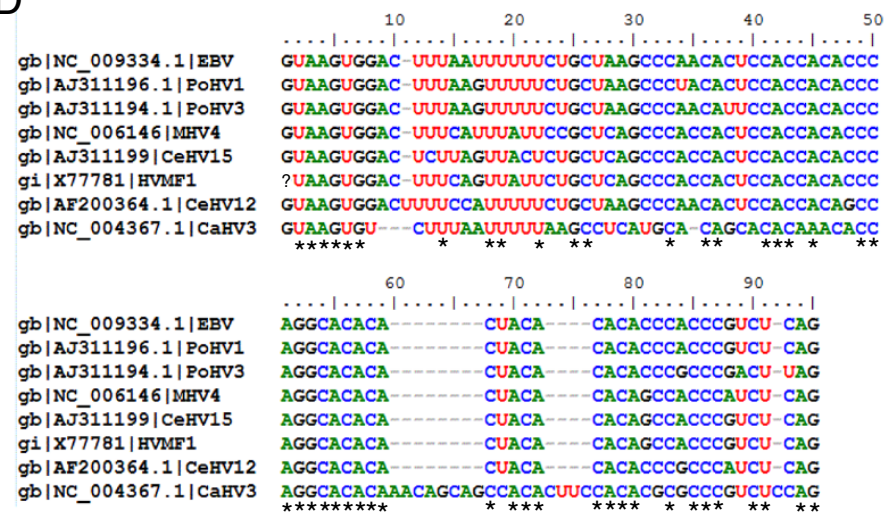

E

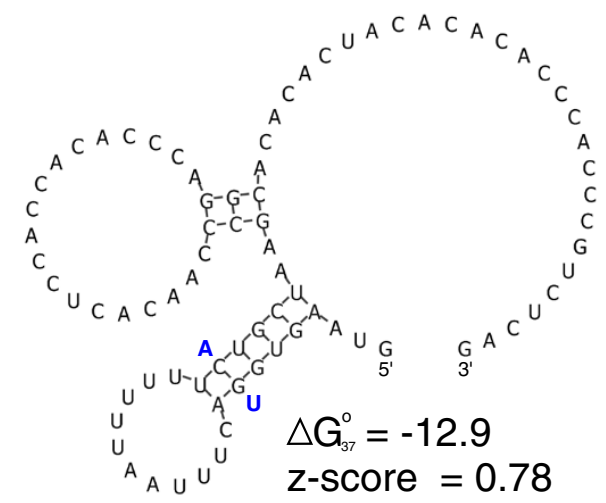

Figure 6 Analyses of ebv-sisRNA-1. (A) Northern blot for ebv-sisRNA-1 using RNA from EBV-negative BJAB cells and from isogenic EBV-positive BJAB-B1 cells. The bottom arrow points to the additional band observed in the EBV-positive BJAB-B1 lane that likely corresponds to the $81 \mathrm{nt}$ ebv-sisRNA-1, while the upper arrow indicates the 106 nt human U6 snRNA (present in both cell types). (B) RT-PCR for EBER1 and ebv-sisRNA-1 using CDNA from BJAB-B1 nuclear RNA and primers complementary to the ends of EBER1 and the 5' end plus nt 52 to 71 of ebv-sisRNA-1. (C) Fold-enrichment in nuclear versus cytoplasmic RNA as measured by RT-qPCR. Shown are the results for the sisRNA and control 185 and U2 snRNA, which are cytoplasmically and nuclearly enriched, respectively. Error bars indicate the standard error of three biological replicates, each with three technical replicates. (D) MAFFT sequence alignment of ebv-sisRNA-1 and those of seven other lymphocryptoviruses: Pongine herpesvirus 1 (PoHV1, AJ311196.1), Pongine herpesvirus 3 (PoHV3, AJ311194.1), Macacine herpesvirus 4 (MHV4, NC_006146), Cercopithicine herpesvirus 15 (CeHV15, AJ311199), Herpesvirus MF-1 from Macaca fascicularis (HVMF1, X77781), Cercopithecine herpesvirus 12 (CeHV12, AF200364.1), and Callitrichine herpesvirus 3 (CaHV3, NC_004367.1). The question mark at the first position in HVMF1 represents missing data, not a true gap. 100\% conserved positions are indicated with stars below the alignment. (E) Predicted structure for ebv-sisRNA-1. Compensatory mutations in the upstream hairpin that convert a GC pair to an AU pair (in CaHV3) are indicated with bold blue nts. This sequence is repeated seven times in EBV: genome (NC_009334.1) coordinates 14603 to 14683,17673 to 17753,20743 to 20823, 23813 to 23893, 26883 to 26963, 29953 to 30033 , and 33023 to 33103.

other herpesviruses a stable intron, known as the latencyassociated transcript (LAT) in HSV-1, is implicated in maintenance of latency [81]. The EBV sisRNA (ebvsisRNA-1) is the first of this class of ncRNAs to be described in EBV. The ebv-sisRNA-1 differs from the LAT in two major respects: the LAT is much larger $(>2 \mathrm{~kb})$, and the functional form of the LAT is believed to be the lariatintron splicing intermediate, whereas the ebv-sisRNA-1 is likely to be a linear molecule. For both ends of ebvsisRNA-1 to have been free for ligation in the small RNA library construction step, the $5^{\prime}$ end of the released intron could not have been sequestered in a lariat structure. This suggests that ebv-sisRNA-1 has been acted upon by the debranching enzyme, which also linearizes intron-derived snoRNAs during the maturation of this important class of ncRNAs [82]. 
Introns homologous to ebv-sisRNA-1 were found in other lymphocryptoviruses (Figure 6D). The ebvsisRNA-1 sequence and these RNAs have an APSI of $83.3 \%$, with the CaHV3 sequence being most distant (57.6\% APSI). In all analyzed EBV strains (EBV-1, EBV-2, GD1, and GD2), the 81 -nt ebv-sisRNA-1 sequence is $100 \%$ conserved, whereas the APSI of the genome sequences of these strains is $95.6 \%$. Within the CA-rich region an 11-nt sequence, from positions 49 to 59 , is $100 \%$ conserved in the analyzed lymphocryptoviruses (Figure 6D). The distribution of dinucleotide frequencies in the ebv-sisRNA-1 sequence is skewed, with $\mathrm{CA}$ being the most frequent, followed by $\mathrm{AC}$ and $\mathrm{CC}$. The presence of CA-rich regions in the sisRNA is interesting as such sequences are able to bind hnRNP L protein and modulate splicing [83].

Although ebv-sisRNA-1 did not overlap an RNAzpredicted region, the secondary structure for this RNA was modeled on the basis of the eight sequences shown in Figure 6E. Two small hairpins are predicted (Figure 6E): an upstream hairpin that places the U-rich motif in a loop and a weak (3 base pair) hairpin in the CA-rich region. A compensatory mutation (double point-mutation that preserves base pairing) is observed in the more stable upstream hairpin (Figure 6E, a conserved GC pair is converted to a UA pair in CaHV3), which suggests that evolution is acting to preserve this structure. It is interesting to find evidence of a conserved hairpin that places the U-rich motif in a loop, as U-rich sequences often bind proteins [84] and hairpins can pre-organize RNA sequence motifs for RNA-protein interactions [85]. The CA-rich region is likely unstructured and free to associate with other interactors.

\section{Additional putative sisRNAs in EBV}

Other than the W repeat sisRNAs, EBV possesses 18 additional short introns (Table 2) interspersed throughout its genome. These short introns range in conservation from $82.9 \%$ to $100.0 \%$ APSI (average of 97.2\%) and are predicted to fold into structures with a range of thermodynamic stabilities (from -0.4 to $-59.6 \mathrm{kcal} / \mathrm{mol}$ ). Four sequences have significantly negative z-scores $[<-1.0$, from nt 11466 to 11610,80362 to 80446,87014 to 87087 , and 105929 to 106056 (Table 2)] and one intron has a moderately favorable z-score (-0.54) from nt 1496 to 1573. These short introns also overlap with RNAz-predicted structured regions (Table 2).

Particularly interesting is the sequence from nt 105929 to 106056, which has the most favorable predicted folding free energy and z-score of any EBV intron (Table 2). This intron occurs within the lytically-expressed BBLF2/3 gene, which generates part of a helix-primase complex essential for replication of the EBV genome [86]. The

Table 2 EBV short intron predicted free energies and z-scores

\begin{tabular}{|c|c|c|c|c|c|c|}
\hline $5^{\prime} \mathrm{nt}$ & $3 ' n t$ & Length & APSI $^{\mathrm{a}}(\%)$ & $\Delta \mathrm{G}(\mathrm{kcal} / \mathrm{mol})$ & Z-score & RNAz \\
\hline 273 & 359 & 87 & 99.4 & -11.9 & 0.77 & \\
\hline 459 & 539 & 81 & 96.9 & -15.1 & 0.56 & \\
\hline 789 & 870 & 82 & 100.0 & -12.7 & 0.25 & \\
\hline 952 & 1025 & 74 & 100.0 & -3.0 & 1.12 & \\
\hline 1197 & 1279 & 83 & 100.0 & -10.9 & 0.24 & \\
\hline 1496 & 1573 & 78 & 99.4 & -20.7 & -0.54 & Locus 2 \\
\hline 11466 & 11610 & 145 & 99.2 & -41.3 & -3.20 & Locus 17 \\
\hline 14939 & 14541 & 149 & 98.2 & -30.7 & 1.45 & \\
\hline $14603^{b}$ & $14683^{b}$ & 81 & 100.0 & -12.9 & 0.78 & \\
\hline 35474 & 35557 & 84 & 97.0 & -4.8 & 0.8 & \\
\hline 71968 & 72073 & 106 & 100.0 & -42.6 & -0.41 & \\
\hline 80362 & 80446 & 85 & 94.3 & -23.1 & -1.12 & Locus 113 \\
\hline 83431 & 83508 & 78 & 97.0 & -9.3 & 1.13 & \\
\hline 87014 & 87087 & 74 & 99.3 & -25.6 & -1.88 & Locus 126 \\
\hline 90856 & 90940 & 85 & 95.9 & -14.5 & -0.02 & \\
\hline 91046 & 91196 & 151 & 82.9 & -47.3 & 1.06 & \\
\hline 105929 & 106056 & 128 & 96.2 & -59.6 & -3.52 & Locus 152 \\
\hline 169949 & 170024 & 76 & 95.0 & -3.3 & 0.64 & \\
\hline 170112 & 170189 & 78 & 98.3 & -0.4 & 0.22 & \\
\hline
\end{tabular}

${ }^{a}$ APSIs calculated for four EBV strains (EBV-1, EBV-2, GD1, and GD2).

${ }^{b}$ Nucleotide numbers for first instance of ebv-sisRNA-1. 
modeled secondary structure of the intron is shown in Figure 7A; it forms a tetraloop hairpin that includes all of the intron sequence. This intron structure is contained within RNAz-predicted locus 152, where the basal stem of the hairpin extends into coding regions by 25 nt (Additional file 3, nt 66692 to 66844 in the reverse genome sequence) and the splice donor and acceptor are base paired within helices. A similar hairpin structure, identified by INFERNAL, occurs in the MHV4 genome
(Figure 7B). Rather than being joined together via splicing, MHV4 BBLF2/3 is translated from two ORFs that produce BBLF2 and BBLF3 as separate proteins. This same intronic region in EBV partially codes for BBLF2 in MHV4 (the translation stop codon occurs within the UUAA tetraloop) and is also present in the 5' UTR of BBLF3 (Figure 7B). It is remarkable that the hairpin structure has been maintained evolutionarily between EBV and MHV4 despite different apparent roles in

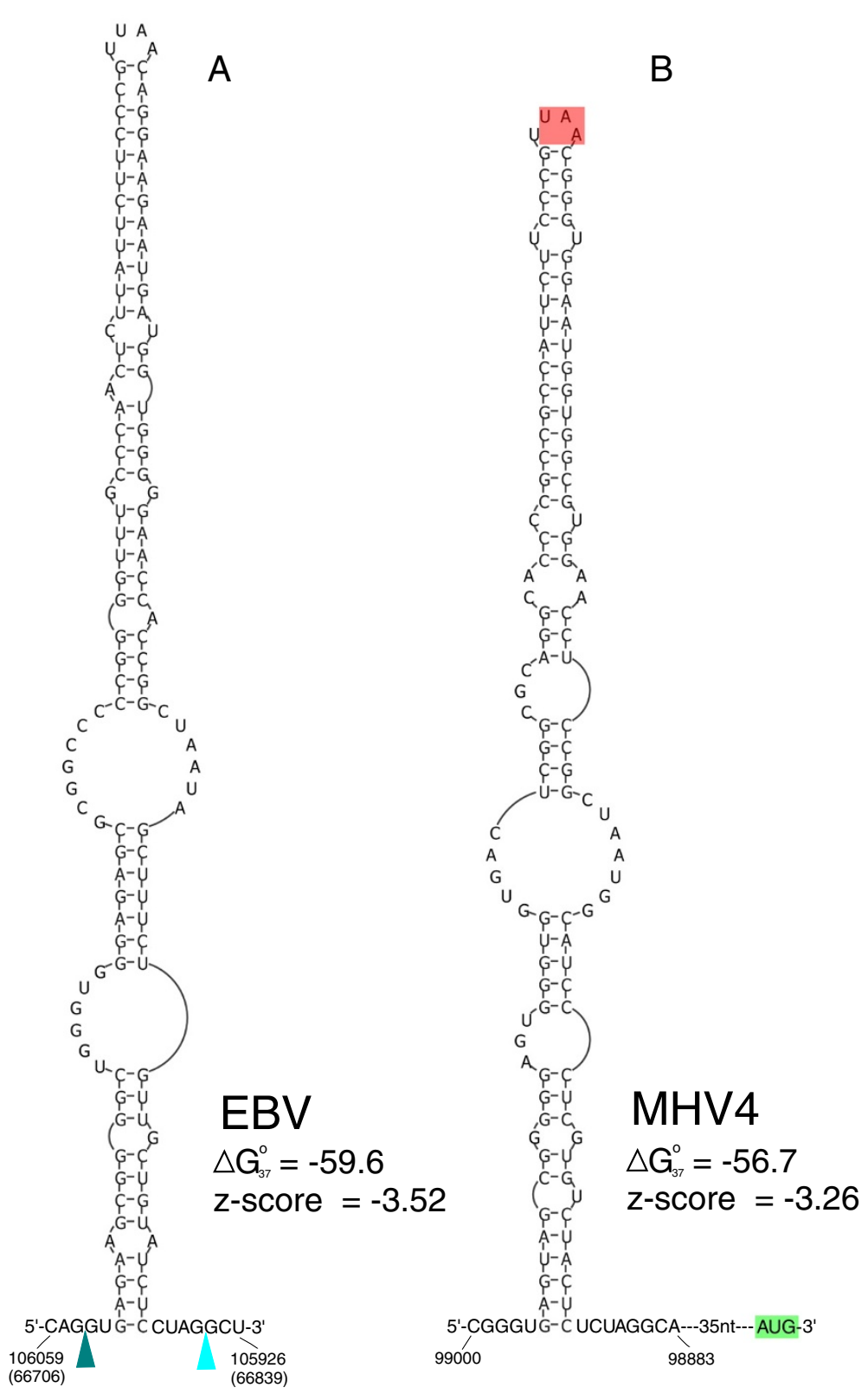

Figure 7 Hairpin structure predicted in BBLF2/3 mRNA. (A) Hairpin modeled for the EBV BBLF2/3 short intron. Splice donor and acceptor sites are indicated with dark and light blue arrows, respectively. Nucleotide numbers in parentheses correspond to the reverse genome strand models in Additional file 3 (locus 152). The predicted free energy (in kcal/mol) and z-score of the hairpin are shown. (B) Homologous hairpin structure in MHV4. The BBLF2 translation stop codon is shaded in red and the BBLF3 start codon is shown in green. 
protein expression: in EBV it brings splice sites closer together in space and may be processed out to form an independent structured RNA, whereas in MHV4 it presents a stop codon in a loop and is not processed out of the mRNA.

Four EBV short introns have significant numbers of mapped reads in the small RNA library (Table 1); however, they are lower in abundance than ebv-sisRNA-1. In the EBV latent membrane protein (LMP-2B) gene, for example, there are three short introns with significant numbers of aligned read peaks (nt 459 to 539, nt 789 to 870, and nt 952 to 1025 in Table 1). Indeed, the intron encompassing nt 952 to 1025 has an abundance of $\sim 5.7 \%$ relative to EBER1, which is similar to the value observed for the v-snoRNA (7.8\%, Table 2). The short introns in EBV, including those that are expressed during latency III and those with few or no mapped reads, may represent a family of sisRNAs. It will be interesting to learn if they are differentially expressed in other viral latency programs or during the lytic phase. Short introns are an attractive source of small ncRNAs, as they are released as byproducts of pre-mRNA splicing.

\section{Structure overlapping splice sites}

The importance of RNA structure in the regulation of splicing has been highlighted in two excellent reviews $[59,87]$. Structure can be inhibitory, by sequestering splice sites [88] or regulatory elements [89], or it can enhance splicing by presenting sites in an accessible conformation [90] or by bringing splice sites into closer proximity with each other [91]. Conformational switching between accessible and inaccessible structures may also regulate splicing [92].

In EBV, there are seven predicted structured regions that include splice sites (Additional file 1). Of these, three include a splice donor or acceptor, while the remaining regions include both sites. For example, in the LMP-2B gene, locus 1 overlaps a splice donor site (after nt 788, Additional file 3), which is buried within the stem of a tetraloop hairpin; towards the $3^{\prime}$ end of this structure (nt 827 to 833 ) is a putative intronic splicing enhancer (Figure 8A). Locus 2 spans an entire intron and includes both the donor and acceptor sites (after nt 1495 and 1573, respectively, in Additional file 3). Additionally, there is a putative exonic splicing enhancer at the beginning of locus 2 (nt 1475 to 1482). The modeled structure for locus 2 (Figure $8 \mathrm{~B}$ ) organizes this region into a complex multibranched structure where the splice donor and acceptor sites are each in helices: the donor at the end of the basal stem and the acceptor within a hairpin loop. Interestingly, each splice site occurs directly after or near a predicted UU/UU twoby-two internal loop motif, in which UU mismatches maintain stable [93,94] helical 3D conformations [95]. Internal loops and non-canonical pairs can present complex patterns of chemical functional groups in proteinaccessible regions of a folded RNA [96], which may influence the binding of splicing factors. Additionally, the 3D folding of this structure may bring splice sites close together.

\section{Structure overlapping coding regions}

Many (150) predictions overlap EBV coding regions, in some cases including a significant portion of an ORF. In the lytically-expressed EBV FGAM-synthase gene, for example, predictions cover $40 \%$ the coding nt (locus 3 to locus 9; Additional file 1). More dramatically, the BGLF3 gene overlaps four predicted structured regions (locus 163 to locus 166; Additional file 1), which span $84 \%$ of the coding region including part of the start codon. Interestingly, many viral genomes appear to be enriched for RNA secondary structure [97,98], including within coding regions $[38,99,100]$. RNA structure in coding regions can have a variety of functions [101], such

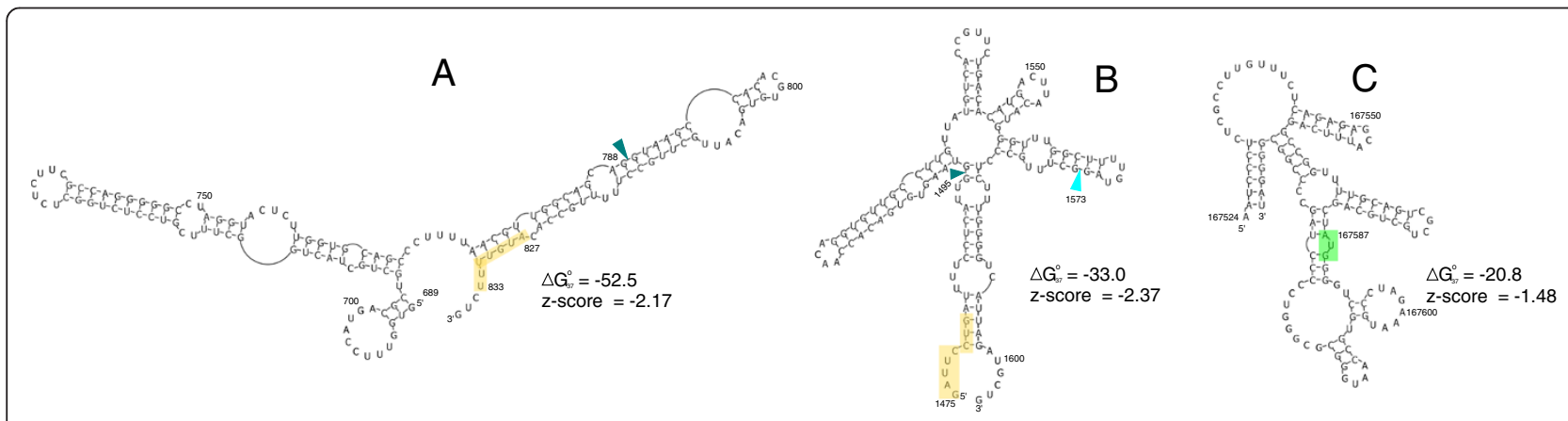

Figure 8 Predicted RNA structures containing splice sites and a start codon. (A) Structure model for RNAz-predicted structural region locus 1 (in LMP-2B gene). The splice donor site is indicated with a dark blue colored wedge and a putative intronic splicing enhancer is colored yellow. (B) Structure model for locus 2 (in the LMP-2B gene). The splicing acceptor site is indicated with the light blue wedge and the yellow box now indicates a putative exonic splicing enhancer. (C) Structure model for locus 263. The start codon for latent membrane protein 2A (LMP-2A) is indicated by the green box. 
as altering reading frames via frame-shifting pseudoknots [37] or by inducing ribosomal pausing [102], which can impact numerous co-translational processes [103,104]. The identification of conserved and stable RNA secondary structures within EBV coding regions suggests that they may play important roles in this virus.

Twenty-one predicted structured regions include translation start or stop codons. Locus 263, for example, includes the start codon for the latent membrane protein 2A (LMP-2A), which is involved in the regulation of host B-cell signaling and is implicated in EBV-associated tumorigenesis [105]. The first $63 \mathrm{nt}$ of locus 263 fall within the 5' UTR of the LMP-2A mRNA (Figure 8C). The start codon is predicted to occur within the stem helix of a multibranch loop. RNA structure can play a role in regulating translation through modulating the accessibility of codons. Strong RNA structure at stop codons, for example, can stimulate stop codon readthrough [106], whereas modulation of start codon accessibility can affect translational efficiency [107]. Perhaps the stable structure ( $\mathrm{z}$-score -1.48 , Figure $8 \mathrm{C}$ ) that encompasses the LMP-2A start codon modulates the expression of this important gene.

\section{Conclusion}

Bioinformatics analyses of the EBV genome revealed 265 regions with putative conserved RNA structure. The computational screen successfully identified most of the known EBV ncRNAs: EBER1, a virally-encoded snoRNA, and 42 miRNAs. Other predicted structured regions of the EBV genome occur at or near sites that suggest potential functions for RNA structures. A very long hairpin structure in the $\mathrm{W}$ repeat region that is conserved in lymphocryptoviruses contains at least one A-to-I editing site, with possible implications for splicing. Additional regions span splice sites or start and stop codons. These structure predictions may prove useful since RNA and RNA structures are attractive targets for chemotherapy [108-111]. The modeled RNA structures are rich in internal loops, e.g. the UU/UU internal loops near two splice sites in LMP-2B, which are potentially drugable structural motifs [112]. RNA splicing, in particular, is an attractive target for RNA therapeutics $[113,114]$.

RNA-Seq data identified several putative sisRNAs, including one in the $\mathrm{W}$ repeat region (ebv-sisRNA-1) that is abundant and localizes in the nucleus. These results lay the groundwork for future experiments to further characterize the proposed structures and to understand the functional significance of the discovered RNAs and RNA structures in EBV. All structural data are available in the Additional files. In addition, data for the W repeat long hairpin and ebv-sisRNA-1 will be deposited in the Rfam database.

\section{Methods}

\section{Structure prediction and modeling}

EBV RefSeq genomes from four different viral strains, EBV-1 (NC_007605.1), EBV-2 (NC_009334.1), GD1 (AY961628.3), and GD2 (HQ020558.1), plus one closely-related genome from Macacine herpesvirus 4 (NC_006146.1), were obtained from the NCBI nt database. Genome sequences were aligned using the MAFFT program $[49,50]$ implementing the FFT-NS-1 alignment strategy. The alignment was processed into 120-nt windows with a 10-nt step-size using the Perl script rnazWindow.pl provided with the RNAz program. Predictions of windows with likely conserved and stable RNA structure were made for both the plus and minus strands with the RNAz $2.1[42,44]$ program using a dinucleotide randomization model. The RNAz output was processed to combine windows with higher probability of structure ( $p$-class $>0.5$ ) into loci. These loci were further filtered to include only those that had at least one window with $\mathrm{p}$-class $>0.9$. When predictions had ambiguous strand orientations, e.g. occurred in a genome location that could be transcribed from either strand, the program RNAstrand [115] was used to determine if structure was more likely to be in the forward or reverse strand.

From each predicted locus the EBV-2 sequence was extracted and used in a BLAST [116] search against the NCBI nt database. The returned homologous sequences were compiled and each locus was aligned using the MAFFT program implementing the Q-INS-i method. Initial models for these alignments were made using RNAalifold [117]. Alignments and predicted consensus structures were converted to Stockholm format alignments and used to build covariance models with the INFERNAL package [64]. These covariance models were used to search for potentially homologous sequences/structures in a database of all available herpesvirus RefSeq genomes. Returned sequences were added to the alignments and structural predictions were made using RNAalifold as well as the program TurboFold [118] followed by manual model refinement. Resulting models were used to perform additional iterative INFERNAL searches and structure revisions until no further model improvement could be made (finding the structure that was best conserved in the alignment).

2D renderings of modeled RNAs were generated using the PseudoViewer program [119] and manually processed using the open-source graphics program Inkscape and ImageJ $[120,121]$. The Gibbs free energy of folding at $37^{\circ} \mathrm{C}[122,123]$ for models was calculated using the efn2 method implemented in the RNAstructure package [124]. The z-scores for sequences were calculated by generating sets of 200 dinucleotide randomizations using the SIMMONICS program [125] and then 
calculating energies with RNAfold [126]. The difference in native free energy versus the randomized set was normalized by the standard deviation to give the z-score.

\section{Small RNA-Seq analysis}

EBV-positive BJAB-B1 cells were maintained at $37^{\circ} \mathrm{C}$ and $5 \% \mathrm{CO}_{2}$ in RPMI media supplemented with FBS (10\%) and penicillin [20]. Cells that had been expanded from $1 \mathrm{ml}$ frozen stock to $200 \mathrm{ml}$ culture volume were grown for an additional $48 \mathrm{hrs}$ and were then pelleted by centrifugation at $1000 \times \mathrm{g}$ for $5 \mathrm{~min}$ at $4^{\circ} \mathrm{C}$. Pellets were washed $3 \times$ with ice-cold PBS buffer (plus DTT). The pellet, on ice, was resuspended in cell disruption buffer [127] $(10 \mathrm{mM} \mathrm{KCl}, 1.5 \mathrm{mM} \mathrm{MgCl} 2,20 \mathrm{mM}$ Tris-Cl, $1 \mathrm{mM}$ DTT, $0.1 \%$ Triton-X) and moved to a chilled Dounce homogenizer (Kontes, type B). Homogenization proceeded on ice until mostly free nuclei were observed under microscope. The lysate was transferred to centrifuge bottles and spun at $1500 \times \mathrm{g}$ for $5 \mathrm{~min}$ at $4^{\circ} \mathrm{C}$. The supernatant, containing the cytoplasmic fraction, was removed to a fresh tube and a $3 \times$ volume of Trizol reagent was added. The nuclear fraction containing pellet was dissolved in $3 \mathrm{ml}$ of Trizol reagent and both fractions were flash frozen in a dry-ice/ethanol bath and stored at $-80^{\circ} \mathrm{C}$ overnight. Each sample was chloroform extracted and then precipitated at room temperature for $10 \mathrm{~min}$ using isopropanol. RNA was pelleted by centrifugation at $10000 \times \mathrm{g}$ for $10 \mathrm{~min}$ at $4^{\circ} \mathrm{C}$. Pellets were resuspended in water and treated with RNase-free DNase I according to manufacturer's protocol (Promega). RNA was further purified/recovered by RNeasy RNA purification kit (Qiagen). Samples were treated again using DNase I to remove any traces of genomic DNA contamination and recovered using the RNeasy kit. RNA integrity was checked using an Agilent BioAnalyzer: the RNA integrity number for the undigested samples was equal to 10, indicating that sample annealing did not degrade the RNA. RNA samples were used to build libraries using a small RNA library kit (Illumina), where specific adapters were ligated to the $5^{\prime}$ and $3^{\prime}$ ends, before barcoding and cDNA synthesis. The cDNA was fragmented and size-selected to contain fragments in the range of 30 to $200 \mathrm{bp}$. RNA-Seq data, 75 bp reads, were acquired on an Illumina HiSeq instrument run in paired-end mode. Reads were aligned to the EBV-2 RefSeq genome (NC_009334.1) using the Bowtie 2 program [128] (data given in Additional file 5).

\section{Analysis of ebv-sisRNA-1 expression}

$20 \mu \mathrm{g}$ of total RNA from EBV-positive BJAB-B1 and EBV-negative (but otherwise isogenic) $B J A B$ cells were fractionated by denaturing 10\% PAGE. RNA was transferred to an Amersham Hybond-N + positively charged nylon membrane then cross-linked to the membrane using UV radiation. The membrane was incubated at $37^{\circ} \mathrm{C}$ for $1 \mathrm{hr}$ in pre-hybridization buffer (GE) and washed $3 \times$ in double-distilled water $\left(\mathrm{ddH}_{2} \mathrm{O}\right)$. The membrane was then incubated overnight at $37^{\circ} \mathrm{C}$ with $5^{\prime}$-radiolabeled DNA probe complementary to nts 37 to 66 of the 106 nt human U6 snRNA (NR_046494.1), probe sequence: 5'-GCAGG GGCCATGCTAATCTTCTCTGTATCG-3'. The blot was washed $3 \times$ in wash buffer $(0.005 \%$ SDS and $3 \times$ SSC), wrapped in plastic film, exposed to a phosphor screen for $16 \mathrm{hrs}$ and imaged on a Storm phosphorimager. The blot was rehybridized with 5'-radiolabeled DNA probe complementary to nt 19 to 46 of ebv-sisRNA-1, probe sequence: 5' - TGTGGTGGAGTGTTGGGCTTA GCAGAAA - 3 '.

For the RT-PCR and RT-qPCR analyses, $2 \mu \mathrm{g}$ nuclear or cytoplasmic RNA were used to generate cDNA with the High Capacity cDNA synthesis kit (Applied Biosystems).

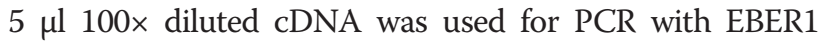
primers complementary to the transcript's $5^{\prime}$ and $3^{\prime}$ ends: FWD 5'-AGGACCTACGCTGCCCTAGA-3' REV 5'-AA AACATGCGGACCACCAGCTGG-3', and ebv-sisRNA-1 primers complementary to the $5^{\prime}$ end and nt 52 to 71 : FWD 5'-GTAAGTGGACTTTAATTTTTTCTGCTAA GCCC-3' REV 5' 'TGGGTGTGTGTAGTGTGTGC-3'. Template was combined with $5 \mu \mathrm{l} 10 \times$ PCR buffer (NEB), $1 \mu \mathrm{l} 10 \mathrm{mM}$ dNTPs, $1 \mu \mathrm{l}$ each of $10 \mu \mathrm{M}$ primer and $0.25 \mu \mathrm{l}$ Taq (NEB) and $\mathrm{ddH}_{2} \mathrm{O}$ to a final volume of $50 \mu \mathrm{l}$. The thermocycler protocol was: (i) initial denaturation at $90^{\circ} \mathrm{C}$ for $10 \mathrm{~min}$, (ii) melt at $90^{\circ} \mathrm{C}$ for $15 \mathrm{~s}$, (iii) anneal at $53^{\circ} \mathrm{C}$ for $30 \mathrm{~s}$, (iv) extend at $60^{\circ} \mathrm{C}$ for $30 \mathrm{~s}$, (v) cycle back to step ii $40 \times$. Amplification products were analyzed by denaturing $10 \%$ PAGE and stained with ethidium bromide. Amplicon sizes were determined by comparison to a 10 bp ladder (Invitrogen).

For RT-qPCR a master mix was made of FastStart Universal SYBR Green Master Mix (Roche), $\mathrm{ddH}_{2} \mathrm{O}$ and each primer (final concentration of $300 \mathrm{nM}$ ). $45 \mu \mathrm{l}$ aliquots were added to a 96-well plate before adding $5 \mu \mathrm{l}$ $100 \times$ dilute cDNA (three biological replicates, each run with three technical replicates, including no template and reverse transcriptase controls). In addition to the ebvsisRNA-1 primers, amplification of nt 8 to 104 of the nuclear-enriched U2 snRNA (NR_002716.3) used primers: FWD 5'-CTCGGCCTTTTGGCTAAGAT-3' REV 5'-TA TTCCATCTCCCTGCTCCA-3'; and nt 994 to 1071 of the cytoplasmically-enriched 18S rRNA (NR_003286.2) used primers: FWD 5'-CGAAAGCATTTGCCAAGA AT-3' REV 5'-GCATCGTTTATGGTCGGAAC-3'. The same thermocycler protocol used for PCR was used for the qPCR run, and data was collected on an Applied Biosystems StepOnePlus Real-Time PCR system. Data were exported to Microsoft Excel and analyzed using the Delta Ct method to find the ratio of nuclear to cytoplasmic abundance. 


\section{Additional files}

Additional file 1: Table showing RNAz-predicted regions with likely stable and conserved RNA structure. Annotated regions (e.g. splice sites and miRNAs) are highlighted in different colors, which match color-annotated structure models provided in Additional file 3 with start and stop codons in green and red, respectively; splice sites in blue; miRNAs in orange; the $W$ repeat hairpin in yellow; EBER1 in purple; and the $v$-snoRNA in brown. The columns for the $5^{\prime}$ and $3^{\prime}$ nt are the first and last nt of the EBV genome (NC_009334.1) that comprise the predicted structured region. The 5' and $3^{\prime}$ nt-Rev numbers indicate the location of structure that likely occurs in RNA transcribed from the reverse genome sequence (corresponding to the structure models shown in the REV_STR worksheet in Additional file 3).

\section{Additional file 2: BED file with locations of RNAz-predicted} structured regions.

\section{Additional file 3: Spreadsheet showing structure models for} predicted EBV structured regions. The sequence shown is for the EBV-2 strain (NC_009334.1). In EBV, transcription can occur from either DNA strand and results for the forward and reverse sense genome sequences are presented in separate worksheets (FWD_STR and REV_STR). RNA structures are in "dot-bracket" notation, with paired sites indicated with matched brackets and unpaired with dots. Colored regions correspond to annotated RNAs in Additional file 1.

Additional file 4: Structure models and predictions of possible A-to-I editing sites (using the Inosine Predict program [70]) for lymphocryptovirus repeat long hairpin RNAs. Each virus has a separate listing with nt position numbered for just the hairpin, followed by the sequence, the secondary structure in dot-bracket notation, the calculated percent editing for four ADAR specificities, and the maximum predicted value of all ADAR specificities. A reported A-to-I editing site [66] is colored red.

Additional file 5: BED file with aligned RNA-Seq reads from BJAB-B1 nuclear small RNA sample.

\section{Abbreviations}

APSI: Average pairwise sequence identity; CaHV3: Callitrichine herpesvirus 3; CeHV12: Cercopithecine herpesvirus 12; EBV: Epstein-Barr virus; MHV4: Macacine herpesvirus 4; miRNA: MicroRNA; ncRNA: Non-coding RNA; nt: Nucleotide(s); sisRNA: Stable intronic sequence RNA; snoRNA: Small nucleolar RNA; v-snoRNA: Viral snoRNA; EBNA: Epstein-Barr nuclear antigen; Cp: C promoter; Wp: W promoter; ORF: Open reading frame; ADAR: Adenosine deaminase acting on RNA; LAT: Latency associated transcript; EBER: Epstein-Barr virus encoded RNA.

\section{Competing interests}

The authors declare that they have no competing interests.

\section{Authors' contributions}

WNM: design and execution of experiments, data analysis/interpretation, and manuscript preparation. JAS: data analysis/interpretation, manuscript preparation, and final approval of the version to be published. All authors read and approved the final manuscript.

\section{Acknowledgements}

We thank Dr. Genaro Pimienta for advice on RNA-Seq data analysis; and Drs. Anna Vilborg and Nara Lee for help with experimental analyses of ebv-sisRNA-1. We also thank Professor Douglas H. Turner (University of Rochester) and Dr. Kazimierz Tycowski for their helpful comments on the manuscript. This work was supported by grant CA16038 from the NIH. JAS is an investigator of the Howard Hughes Medical Institute.

Received: 20 June 2013 Accepted: 7 August 2013

Published: 9 August 2013

\section{References}

1. Epstein-Barr virus and infectious mononucleosis. http://www.cdc.gov/ncidod/ diseases/ebv.htm

2. Flavell KJ, Murray PG: Hodgkin's disease and the Epstein-Barr virus. Mol Pathol: MP 2000, 53(5):262-269.
3. Burgos JS: Involvement of the Epstein-Barr virus in the nasopharyngeal carcinoma pathogenesis. Med Oncol 2005, 22(2):113-121.

4. Akhter S, Liu H, Prabhu R, DeLucca C, Bastian F, Garry RF, Schwartz M, Thung SN, Dash S: Epstein-Barr virus and human hepatocellular carcinoma. Cancer Letters 2003, 192(1):49-57.

5. Begin LR, Eskandari J, Joncas J, Panasci L: Epstein-Barr virus related lymphoepithelioma-like carcinoma of lung. J Surg Oncol 1987, 36(4):280-283.

6. Hippocrate A, Oussaief L, Joab I: Possible role of EBV in breast cancer and other unusually EBV-associated cancers. Cancer Letters 2011, 305(2):144-149.

7. Wen S, Shimizu N, Yoshiyama H, Mizugaki Y, Shinozaki F, Takada K: Association of Epstein-Barr virus (EBV) with Sjogren's syndrome: differential EBV expression between epithelial cells and lymphocytes in salivary glands. Am J Pathol 1996, 149(5):1511-1517.

8. Chen DY, Chen YM, Lan JL, Chen HH, Hsieh CW, Wey SJ, Lu JJ: Polymyositis/dermatomyositis and nasopharyngeal carcinoma: the Epstein-Barr virus connection? J Clin Virol 2010, 49(4):290-295.

9. Parks CG, Cooper GS, Hudson LL, Dooley MA, Treadwell EL, St Clair EW, Gilkeson GS, Pandey JP: Association of Epstein-Barr virus with systemic lupus erythematosus: effect modification by race, age, and cytotoxic T lymphocyte-associated antigen 4 genotype. Arthritis Rheum 2005, 52(4):1148-1159.

10. Alspaugh MA, Jensen FC, Rabin H, Tan EM: Lymphocytes transformed by Epstein-Barr virus. Induction of nuclear antigen reactive with antibody in rheumatoid arthritis. J Exp Med 1978, 147(4):1018-1027.

11. Levin LI, Munger KL, Rubertone MV, Peck CA, Lennette ET, Spiegelman D, Ascherio A: Multiple sclerosis and Epstein-Barr virus. JAMA: J Am Med Assoc 2003, 289(12):1533-1536.

12. Epstein MA, Achong BG, Barr YM: Virus particles in cultured lymphoblasts from Burkitt's lymphoma. Lancet 1964, 1(7335):702-703.

13. Burkitt D: A sarcoma involving the jaws in African children. Brit J Surg 1958, 46(197):218-223.

14. Young LS, Dawson CW, Eliopoulos AG: The expression and function of Epstein-Barr virus encoded latent genes. Mol Pathol: MP 2000 53(5):238-247

15. Ning S: Innate immune modulation in EBV infection. Herpesviridae 2011, 2(1):1

16. Takada K: Role of Epstein-Barr virus in Burkitt's lymphoma. Curr Top Microbiol Immunol 2001, 258:141-151.

17. Young LS, Arrand JR, Murray PG: EBV gene expression and regulation. In Human Herpes viruses: biology, therapy, and immunoprophylaxis. Edited by Arvin A, Campadelli-Fiume G, Mocarski E, Moore PS, Roizman B, Whitley R, Yamanishi K. Cambridge: Cambridge University Press; 2007.

18. Lerner MR, Andrews NC, Miller G, Steitz JA: Two small RNAs encoded by Epstein-Barr virus and complexed with protein are precipitated by antibodies from patients with systemic lupus erythematosus. Proc Natl Acad Sci USA 1981, 78(2):805-809.

19. Chen SJ, Chen GH, Chen YH, Liu CY, Chang KP, Chang YS, Chen HC: Characterization of Epstein-Barr virus miRNAome in nasopharyngeal carcinoma by deep sequencing. PloS One 2010, 5(9):e12745. doi:10.1371/ journal.pone.0012745.

20. Riley KJ, Rabinowitz GS, Yario TA, Luna JM, Darnell RB, Steitz JA: EBV and human microRNAs co-target oncogenic and apoptotic viral and human genes during latency. EMBO J 2012, 31(9):2207-2221.

21. Yoshizaki T, Endo K, Ren Q, Wakisaka N, Murono S, Kondo S, Sato H, Furukawa M: Oncogenic role of Epstein-Barr virus-encoded small RNAs (EBERs) in nasopharyngeal carcinoma. Auris, Nasus, Larynx 2007, 34(1):73-78.

22. Yamamoto N, Takizawa T, Iwanaga $Y$, Shimizu N: Malignant transformation of $B$ lymphoma cell line BJAB by Epstein-Barr virus-encoded small RNAs. FEBS Letters 2000, 484(2):153-158.

23. Conrad NK, Fok V, Cazalla D, Borah S, Steitz JA: The challenge of viral snRNPs. Cold Spring Harb Symp Quant Biol 2006, 71:377-384.

24. Fok V, Mitton-Fry RM, Grech A, Steitz JA: Multiple domains of EBER 1, an Epstein-Barr virus noncoding RNA, recruit human ribosomal protein L22. RNA 2006, 12(5):872-882

25. Toczyski DP, Matera AG, Ward DC, Steitz JA: The Epstein-Barr virus (EBV) small RNA EBER1 binds and relocalizes ribosomal protein L22 in EBV-infected human B lymphocytes. Proc Natl Acad Sci USA 1994, 91(8):3463-3467. 
26. Lee N, Pimienta G, Steitz JA: AUF1/hnRNP D is a novel protein partner of the EBER1 noncoding RNA of Epstein-Barr virus. RNA 2012, 18(11):2073-2082.

27. Glickman JN, Howe JG, Steitz JA: Structural analyses of EBER1 and EBER2 ribonucleoprotein particles present in Epstein-Barr virus-infected cells. J Virol 1988, 62(3):902-911.

28. Pfingsten JS, Costantino DA, Kieft JS: Structural basis for ribosome recruitment and manipulation by a viral IRES RNA. Science 2006, 314(5804):1450-1454.

29. Butcher SE: Structure and function of the small ribozymes. Curr Opin Struct Biol 2001, 11(3):315-320.

30. Johnson SF, Telesnitsky A: Retroviral RNA dimerization and packaging: the what, how, when, where, and why. PLoS Pathog 2010, 6(10):e1001007.

31. Abbink TE, Berkhout B: RNA structure modulates splicing efficiency at the human immunodeficiency virus type 1 major splice donor. J Virol 2008, 82(6):3090-3098

32. Moss WN, Dela-Moss LI, Priore SF, Turner DH: The influenza A segment 7 mRNA 3' splices site pseudoknot/hairpin family. RNA Biol 2012, 9(11):1305-1310.

33. Malathi K, Saito T, Crochet N, Barton DJ, Gale M Jr, Silverman RH: RNase L releases a small RNA from HCV RNA that refolds into a potent PAMP. RNA 2010, 16(11):2108-2119.

34. Conrad NK, Shu MD, Uyhazi KE, Steitz JA: Mutational analysis of a viral RNA element that counteracts rapid RNA decay by interaction with the polyadenylate tail. Proc Natl Acad Sci USA 2007, 104(25):10412-10417.

35. Mitton-Fry RM, DeGregorio SJ, Wang J, Steitz TA, Steitz JA: Poly (A) tail recognition by a viral RNA element through assembly of a triple helix. Science 2010, 330(6008):1244-1247.

36. Tycowski KT, Shu MD, Borah S, Shi M, Steitz JA: Conservation of a triplehelix-forming RNA stability element in noncoding and genomic RNAs of diverse viruses. Cell Rep 2012, 2(1):26-32.

37. Giedroc DP, Cornish PV: Frameshifting RNA pseudoknots: structure and mechanism. Virus Res 2009, 139(2):193-208.

38. Moss WN, Priore SF, Turner DH: Identification of potential conserved RNA secondary structure throughout influenza A coding regions. RNA 2011, 17(6):991-1011.

39. Hofacker IL, Fekete M, Flamm C, Huynen MA, Rauscher S, Stolorz PE, Stadler PF: Automatic detection of conserved RNA structure elements in complete RNA virus genomes. Nucleic Acids Res 1998, 26(16):3825-3836.

40. Tuplin A, Wood J, Evans DJ, Patel AH, Simmonds P: Thermodynamic and phylogenetic prediction of RNA secondary structures in the coding region of hepatitis C virus. RNA 2002, 8(6):824-841.

41. Mathews DH, Moss WN, Turner DH: Folding and finding RNA secondary structure. Cold Spring Harb Perspect Biol 2010, 2(12):a003665.

42. Washietl S, Hofacker IL, Stadler PF: Fast and reliable prediction of noncoding RNAs. Proc Natl Acad Sci USA 2005, 102(7):2454-2459.

43. Schroeder SJ: Advances in RNA structure prediction from sequence: new tools for generating hypotheses about viral RNA structure-function relationships. J Virol 2009, 83(13):6326-6334.

44. Gruber AR, Findeiss S, Washietl S, Hofacker IL, Stadler PF: RNAz 2.0: improved noncoding RNA detection. Pac Symp Biocomp 2010, 15:69-79.

45. Clote P, Ferre F, Kranakis E, Krizanc D: Structural RNA has lower folding energy than random RNA of the same dinucleotide frequency. RNA 2005, 11(5):578-591

46. Hofacker IL, Stadler PF, Stocsits RR: Conserved RNA secondary structures in viral genomes: a survey. Bioinformatics 2004, 20(10):1495-1499.

47. Lodeiro MF, Filomatori CV, Gamarnik AV: Structural and functional studies of the promoter element for dengue virus RNA replication. J Virol 2009, 83(2):993-1008.

48. Cordey S, Gerlach D, Junier T, Zdobnov EM, Kaiser L, Tapparel C: The cisacting replication elements define human enterovirus and rhinovirus species. RNA 2008, 14(8):1568-1578.

49. Katoh K, Kuma K, Toh H, Miyata T: MAFFT version 5: improvement in accuracy of multiple sequence alignment. Nucleic Acids Res 2005, 33 (2):511-518.

50. Katoh K, Misawa K, Kuma K, Miyata T: MAFFT: a novel method for rapid multiple sequence alignment based on fast Fourier transform. Nucleic Acids Res 2002, 30(14):3059-3066.

51. Ehlers B, Spiess K, Leendertz F, Peeters M, Boesch C, Gatherer D, McGeoch DJ: Lymphocryptovirus phylogeny and the origins of Epstein-Barr virus. J Gen Virol 2010, 91(Pt 3):630-642.
52. Hutzinger R, Feederle R, Mrazek J, Schiefermeier N, Balwierz PJ, Zavolan M, Polacek N, Delecluse HJ, Huttenhofer A: Expression and processing of a small nucleolar RNA from the Epstein-Barr virus genome. PLoS Pathog 2009, 5(8):e1000547.

53. Griffiths-Jones S, Saini HK, van Dongen S, Enright AJ: miRBase: tools for microRNA genomics. Nucleic Acids Res 2008, 36(Database issue):D154-D158.

54. Rearick D, Prakash A, McSweeny A, Shepard SS, Fedorova L, Fedorov A: Critical association of ncRNA with introns. Nucleic Acids Res 2011, 39(6):2357-2366.

55. St Laurent G, Shtokalo D, Tackett MR, Yang Z, Eremina T, Wahlestedt C, Urcuqui-Inchima S, Seilheimer B, McCaffrey TA, Kapranov P: Intronic RNAs constitute the major fraction of the non-coding RNA in mammalian cells. BMC Genomics 2012, 13:504.

56. Dieci G, Preti M, Montanini B: Eukaryotic snoRNAs: a paradigm for gene expression flexibility. Genomics 2009, 94(2):83-88.

57. Lin SL, Kim H, Ying SY: Intron-mediated RNA interference and microRNA (miRNA). Front Biosci 2008, 13:2216-2230.

58. Beyret $\mathrm{E}$, Liu $\mathrm{N}$, Lin $\mathrm{H}$ : piRNA biogenesis during adult spermatogenesis in mice is independent of the ping-pong mechanism. Cell Res 2012, 22(10):1429-1439.

59. Warf $M B$, Berglund JA: Role of RNA structure in regulating pre-mRNA splicing. Trends Biochem Sci 2010, 35(3):169-178.

60. Tierney RJ, Kao KY, Nagra JK, Rickinson AB: Epstein-Barr virus BamHI W repeat number limits EBNA2/EBNA-LP coexpression in newly infected $B$ cells and the efficiency of B-cell transformation: a rationale for the multiple W repeats in wild-type virus strains. J Virol 2011, 85(23):12362-12375.

61. Concha M, Wang X, Cao S, Baddoo M, Fewell C, Lin Z, Hulme W, Hedges D, McBride J, Flemington EK: Identification of new viral genes and transcript isoforms during Epstein-Barr virus reactivation using RNA-Seq. J Virol 2012, 86(3):1458-1467.

62. Woisetschlaeger M, Yandava CN, Furmanski LA, Strominger JL, Speck SH: Promoter switching in Epstein-Barr virus during the initial stages of infection of B lymphocytes. Proc Natl Acad Sci USA 1990, 87(5):1725-1729.

63. Rogers RP, Woisetschlaeger M, Speck SH: Alternative splicing dictates translational start in Epstein-Barr virus transcripts. EMBO J 1990, 9(7):2273-2277.

64. Nawrocki EP, Kolbe DL, Eddy SR: Infernal 1.0: inference of RNA alignments. Bioinformatics 2009, 25(10):1335-1337.

65. Gardner PP: The use of covariance models to annotate RNAs in whole genomes. Brief Funct Genomic Proteomic 2009, 8(6):444-450.

66. Arvey A, Tempera I, Tsai K, Chen HS, Tikhmyanova N, Klichinsky M, Leslie C, Lieberman PM: An atlas of the Epstein-Barr virus transcriptome and epigenome reveals host-virus regulatory interactions. Cell Host Microbe 2012, 12(2):233-245.

67. Lerman YV, Kennedy SD, Shankar N, Parisien M, Major F, Turner DH: NMR structure of a $4 \times 4$ nucleotide RNA internal loop from an R2 retrotransposon: identification of a three purine-purine sheared pair motif and comparison to MC-SYM predictions. RNA 2011, 17(9):1664-1677.

68. Morse DP, Aruscavage PJ, Bass BL: RNA hairpins in noncoding regions of human brain and Caenorhabditis elegans mRNA are edited by adenosine deaminases that act on RNA. Proc Natl Acad Sci USA 2002, 99(12):7906-7911.

69. Morse DP, Bass BL: Long RNA hairpins that contain inosine are present in Caenorhabditis elegans poly (A) + RNA. Proc Natl Acad Sci USA 1999, 96(11):6048-6053.

70. Eggington JM, Greene T, Bass BL: Predicting sites of ADAR editing in double-stranded RNA. Nat Commun 2011, 2:319.

71. Kim DD, Kim TT, Walsh T, Kobayashi Y, Matise TC, Buyske S, Gabriel A: Widespread RNA editing of embedded alu elements in the human transcriptome. Genome Res 2004, 14(9):1719-1725.

72. Lev-Maor G, Ram O, Kim E, Sela N, Goren A, Levanon EY, Ast G: Intronic Alus influence alternative splicing. PLoS Genet 2008, 4(9):e1000204.

73. Bond CS, Fox AH: Paraspeckles: nuclear bodies built on long noncoding RNA. J Cell Biol 2009, 186(5):637-644.

74. Fresen $\mathrm{KO}$, Hausen $\mathrm{H}$ : Establishment of EBNA-expressing cell lines by infection of Epstein-Barr virus (EBV)-genome-negative human lymphoma cells with different EBV strains. Int J Cancer J Int du Cancer 1976, 17(2):161-166.

75. Howe JG, Steitz JA: Localization of Epstein-Barr virus-encoded small RNAs by in situ hybridization. Proc Natl Acad Sci USA 1986, 83(23):9006-9010.

76. Thorvaldsdottir H, Robinson JT, Mesirov JP: Integrative Genomics Viewer (IGV): high-performance genomics data visualization and exploration. Brief Bioinform 2013, 14(2):178-192. 
77. Robinson JT, Thorvaldsdottir H, Winckler W, Guttman M, Lander ES, Getz G, Mesirov JP: Integrative genomics viewer. Nat Biotechnol 2011, 29(1):24-26.

78. Gardner EJ, Nizami ZF, Talbot CC Jr, Gall JG: Stable intronic sequence RNA (sisRNA), a new class of noncoding RNA from the oocyte nucleus of Xenopus tropicalis. Genes Dev 2012, 26(22):2550-2559.

79. Farrell MJ, Dobson AT, Feldman LT: Herpes simplex virus latencyassociated transcript is a stable intron. Proc Natl Acad Sci USA 1991, 88(3):790-794.

80. Kulesza CA, Shenk T: Murine cytomegalovirus encodes a stable intron that facilitates persistent replication in the mouse. Proc Natl Acad Sci USA 2006, 103(48):18302-18307.

81. Hesselberth JR: Lives that introns lead after splicing. WIRES RNA 2013 doi:10.1002/wrna.1187.

82. Petfalski E, Dandekar T, Henry Y, Tollervey D: Processing of the precursors to small nucleolar RNAs and rRNAs requires common components. Mol Cell Biol 1998, 18(3):1181-1189.

83. Hui J, Hung LH, Heiner M, Schreiner S, Neumuller N, Reither G, Haas SA, Bindereif A: Intronic CA-repeat and CA-rich elements: a new class of regulators of mammalian alternative splicing. EMBO J 2005, 24(11):1988-1998.

84. You Y, Chen CY, Shyu AB: U-rich sequence-binding proteins (URBPs) interacting with a 20-nucleotide U-rich sequence in the $3^{\prime}$ untranslated region of c-fos mRNA may be involved in the first step of c-fos mRNA degradation. Mol Cell Biol 1992, 12(7):2931-2940.

85. Alian A, DeGiovanni A, Griner SL, Finer-Moore JS, Stroud RM: Crystal structure of an RluF-RNA complex: a base-pair rearrangement is the key to selectivity of RluF for U2604 of the ribosome. J Mol Biol 2009, 388(4):785-800.

86. Liao G, Huang J, Fixman ED, Hayward SD: The Epstein-Barr virus replication protein $B B L F 2 / 3$ provides an origin-tethering function through interaction with the zinc finger DNA binding protein ZBRK1 and the KAP-1 corepressor. J Virol 2005, 79(1):245-256.

87. Buratti $E$, Baralle FE: Influence of RNA secondary structure on the premRNA splicing process. Mol Cell Biol 2004, 24(24):10505-10514.

88. Blanchette $M$, Chabot $B$ : A highly stable duplex structure sequesters the $5^{\prime}$ splice site region of hnRNP A1 alternative exon 7B. RNA 1997, 3(4):405-419.

89. Sirand-Pugnet $P$, Durosay P, Clouet d'Orval BC, Brody E, Marie J: BetaTropomyosin pre-mRNA folding around a muscle-specific exon interferes with several steps of spliceosome assembly. J Mol Biol 1995 251(5):591-602.

90. Buratti E, Muro AF, Giombi M, Gherbassi D, laconcig A, Baralle FE: RNA folding affects the recruitment of SR proteins by mouse and human polypurinic enhancer elements in the fibronectin EDA exon. Mol Cell Biol 2004, 24(3):1387-1400.

91. Libri D, Stutz F, McCarthy T, Rosbash M: RNA structural patterns and splicing: molecular basis for an RNA-based enhancer. RNA 1995, 1(4):425-436.

92. Moss WN, Dela-Moss LI, Kierzek E, Kierzek R, Priore SF, Turner DH: The 3' splice site of influenza A segment 7 mRNA can exist in two conformations: a pseudoknot and a hairpin. PloS One 2012, 7(6):e38323.

93. SantaLucia J Jr, Kierzek R, Turner DH: Stabilities of consecutive A.C, C. C, G.G, U.C, and U.U mismatches in RNA internal loops: Evidence for stable hydrogen-bonded U.U and C.C. + pairs. Biochemistry 1991, 30(33):8242-8251

94. Wu M, McDowell JA, Turner DH: A periodic table of symmetric tandem mismatches in RNA. Biochemistry 1995, 34(10):3204-3211.

95. Sashital DG, Venditti V, Angers CG, Cornilescu G, Butcher SE: Structure and thermodynamics of a conserved U2 snRNA domain from yeast and human. RNA 2007, 13(3):328-338

96. Hermann T, Westhof E: Non-Watson-Crick base pairs in RNA-protein recognition. Chem Biol 1999, 6(12):R335-R343.

97. Simmonds P, Tuplin A, Evans DJ: Detection of genome-scale ordered RNA structure (GORS) in genomes of positive-stranded RNA viruses: implications for virus evolution and host persistence. RNA 2004, 10(9):1337-1351.

98. Priore SF, Moss WN, Turner DH: influenza A virus coding regions exhibit host-specific global ordered RNA structure. PloS One 2012, 7(4):e35989.

99. Cuceanu NM, Tuplin A, Simmonds P: Evolutionarily conserved RNA secondary structures in coding and non-coding sequences at the $3^{\prime}$ end of the hepatitis G virus/GB-virus C genome. J Gen Virol 2001 82(Pt 4):713-722.
100. Clyde K, Harris E: RNA secondary structure in the coding region of dengue virus type 2 directs translation start codon selection and is required for viral replication. J Virol 2006, 80(5):2170-2182.

101. Mao Y, Li Q, Wang W, Liang P, Tao S: Number variation of high stability regions is correlated with gene functions. Genome Biol Evol 2013, 5(3):484-493.

102. Wen JD, Lancaster L, Hodges C, Zeri AC, Yoshimura SH, Noller HF, Bustamante C, Tinoco I: Following translation by single ribosomes one codon at a time. Nature 2008, 452(7187):598-603.

103. Cabrita LD, Dobson CM, Christodoulou J: Protein folding on the ribosome. Curr Opin Struct Biol 2010, 20(1):33-45.

104. Siller E, DeZwaan DC, Anderson JF, Freeman BC, Barral JM: Slowing bacterial translation speed enhances eukaryotic protein folding efficiency. J Mol Biol 2010, 396(5):1310-1318.

105. Fukuda $M$, Longnecker $R$ : Epstein-Barr virus latent membrane protein $2 A$ mediates transformation through constitutive activation of the Ras/PI3 K/Akt pathway. J Virol 2007, 81(17):9299-9306.

106. Firth AE, Wills NM, Gesteland RF, Atkins JF: Stimulation of stop codon readthrough: frequent presence of an extended 3' RNA structural element. Nucleic Acids Res 2011, 39(15):6679-6691.

107. Gu W, Zhou T, Wilke CO: A universal trend of reduced mRNA stability near the translation-initiation site in prokaryotes and eukaryotes. PLoS Comput Biol 2010, 6(2):e1000664

108. Das A, Bhadra K, Suresh Kumar G: Targeting RNA by small molecules: comparative structural and thermodynamic aspects of aristololactambeta-D-glucoside and daunomycin binding to tRNA (phe). PloS One 2011, 6(8):e23186.

109. Stelzer AC, Frank AT, Kratz JD, Swanson MD, Gonzalez-Hernandez MJ, Lee J, Andricioaei I, Markovitz DM, Al-Hashimi HM: Discovery of selective bioactive small molecules by targeting an RNA dynamic ensemble. Nat Chem Biol 2011, 7(8):553-559.

110. Pushechnikov A, Lee MM, Childs-Disney JL, Sobczak K, French JM, Thornton CA Disney MD: Rational design of ligands targeting triplet repeating transcripts that cause RNA dominant disease: application to myotonic muscular dystrophy type 1 and spinocerebellar ataxia type 3. J Am Chem Soc 2009, 131(28):9767-9779.

111. Childs JL, Disney MD, Turner DH: Oligonucleotide directed misfolding of RNA inhibits Candida albicans group I intron splicing. Proc Natl Acad Sci USA 2002, 99(17):11091-11096.

112. Childs-Disney JL, Wu M, Pushechnikov A, Aminova O, Disney MD: A small molecule microarray platform to select RNA internal loop-ligand interactions. ACS Chem Biol 2007, 2(11):745-754.

113. Havens MA, Duelli DM, Hastings ML: Targeting RNA splicing for disease therapy. WIRES RNA 2013, 4:247-266. doi:10.1002/wrna.1158.

114. Zhou J, Zheng $X$, Shen H: Targeting RNA-splicing for SMA treatment. Mol Cells 2012, 33(3):223-228

115. Reiche K, Stadler PF: RNAstrand: reading direction of structured RNAs in multiple sequence alignments. Algor Mol Biol: AMB 2007, 2:6.

116. Altschul SF, Gish W, Miller W, Myers EW, Lipman DJ: Basic local alignment search tool. J Mol Biol 1990, 215(3):403-410.

117. Bernhart SH, Hofacker IL, Will S, Gruber AR, Stadler PF: RNAalifold: improved consensus structure prediction for RNA alignments. BMC Bioinformatics 2008, 9:474.

118. Harmanci AO, Sharma G, Mathews DH: TurboFold: iterative probabilistic estimation of secondary structures for multiple RNA sequences. BMC Bioinformatics 2011, 12:108.

119. Han K, Lee Y, Kim W: PseudoViewer: automatic visualization of RNA pseudoknots. Bioinformatics 2002, 18(Suppl 1):S321-S328.

120. Schneider CA, Rasband WS, Eliceiri KW: NIH Image to ImageJ: 25 years of image analysis. Nat Methods 2012, 9(7):671-675.

121. Girish V, Vijayalakshmi A: Affordable image analysis using NIH Image/ ImageJ. Indian J Cancer 2004, 41(1):47.

122. Turner $\mathrm{DH}$, Mathews $\mathrm{DH}$ : NNDB: the nearest neighbor parameter database for predicting stability of nucleic acid secondary structure. Nucleic Acids Res 2010, 38(Database issue):D280-D282.

123. Mathews DH, Disney MD, Childs JL, Schroeder SJ, Zuker M, Turner DH: Incorporating chemical modification constraints into a dynamic programming algorithm for prediction of RNA secondary structure. Proc Natl Acad Sci USA 2004, 101(19):7287-7292.

124. Reuter JS, Mathews DH: RNAstructure: software for RNA secondary structure prediction and analysis. BMC Bioinformatics 2010, 11:129. 
125. Simmonds P: SSE: a nucleotide and amino acid sequence analysis platform. BMC Res Notes 2012, 5:50.

126. Gruber AR, Lorenz R, Bernhart SH, Neubock R, Hofacker IL: The Vienna RNA websuite. Nucleic Acids Res 2008, 36(Web Server issue):W70-W74

127. Rio DC, Ares M Jr, Hannon GJ, Nilsen TW: Preparation of cytoplasmic and nuclear RNA from tissue culture cells. Cold Spring Harb Protoc 2010, 2010(6). doi:10.1101/pdb.prot5441.

128. Langmead B, Salzberg SL: Fast gapped-read alignment with bowtie 2 . Nat Methods 2012, 9(4):357-359.

doi:10.1186/1471-2164-14-543

Cite this article as: Moss and Steitz: Genome-wide analyses of Epstein-

Barr virus reveal conserved RNA structures and a novel stable intronic sequence RNA. BMC Genomics 2013 14:543.

\section{Submit your next manuscript to BioMed Central and take full advantage of:}

- Convenient online submission

- Thorough peer review

- No space constraints or color figure charges

- Immediate publication on acceptance

- Inclusion in PubMed, CAS, Scopus and Google Scholar

- Research which is freely available for redistribution 